\title{
Manajemen Kepemimpinan Pendidikan: Analisis Untuk Mewujudkan Keunggulan Kompetitif
}

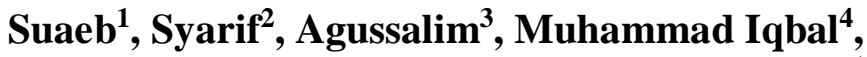 \\ Sekolah Tinggi Keguruan dan Ilmu Pendidikan Bima ${ }^{1,3,4}$ \\ Sekolah Tinggi Ilmu Sosial dan Ilmu Politik Mbojo Bima² \\ E-mail: suaebngali@gmail.com ${ }^{1}$, syarifahmad1975@gmail.com²,$\underline{\text { agussalimmpd08@gmail.com }}$, \\ nhacoacho@gmail.com ${ }^{3}$
}

\begin{abstract}
This study focuses on the study of educational leadership management at the school organization level. The purpose of this study is to analyze leadership management indicators that determine school excellence. This study uses the library research method, namely by collecting relevant data from books, journals, magazines, and so on without having to conduct field reviews. The time of this research was carried out for three months, starting with collecting books and journals, then analyzing the suitability of the research topic and theme with the theme of this research. Based on the results of the analysis of scientific books and journals used in the study, the indicators of leadership management to realize school excellence include: organizational aspects, learning, resources (human and infrastructure), and organizational culture. These indicators are the determinants of school excellence. So school leaders should focus more attention focused on the fulfillment of these indicators.
\end{abstract}

Keywords: Leadership Management, Competitive Advantage

Abstrak: Studi ini difokuskan pada kajian tentang manajemen kepemimpinan pendidikan pada tingkat organisasi sekolah. Tujuan dari studi ini adalah menganalisis indikator-indikator manajemen kepemimpinan yang menentukan keunggulan sekolah. Penelitian ini menggunakan metode library research (penelitian kepustakaan), yakni dengan cara mengumpulkan data-data yang relevan dari buku, jurnal, majalah, dan lain sebagainya tanpa harus melakukan tinjauan ke lapangan. Waktu penelitian ini dilaksanakan selama tiga bulan, dimulai dengan melakukan pengumpulan terhadap buku-buku dan jurnal, kemudian analisis kesesuaian topik dan tema riset dengan tema penelitian ini. Berdasarkan hasil analisis terhadap buku-buku dan jurnal ilmiah yang digunakan dalam penelitian bahwa indikator manajemen kepemimpinan untuk mewujudkan keunggulan sekolah, yakni mencakup: aspek organisasi, pembelajaran, sumber daya (manusia dan sarana prasarana), dan budaya organisasi. Indikator tersebut menjadi penentu bagi keunggulan sekolah. Sehingga para pemimpin sekolah harus lebih banyak menaruh fokus perhatian difokuskan pada terpenuhinya indikator-indikator tersebut.

Kata kunci: Manajemen Kepemimpinan, Keunggulan Kompetitif

\section{PENDAHULUAN}

Variabel kepemimpinan memainkan peran penting dalam mewujudkan perubahan tatakelola organisasi. Studi terhadap gaya kepemimpinan dalam organisasi pendidikan telah banyak dilakukan, dengan berbagai pendekatan penelitian yang digunakan, baik pendekatan kualitatif maupun kuantitatif. Sebagaimana Jackson (2019) yang melakukan studi eksplorasi terhadap aspek metodologi penelitian untuk artikel yang diterbitkan dalam tiga jurnal kepemimpinan pendidikan, dimana artikel yang diterbitkan antara tahun 2013 sampai 2017, menunjukkan bahwa pilihan desain metodologis lebih banyak menggunakan metode kualitatif daripada metode kuantitatif dan campuran. Artinya, studi tentang kepemimpinan telah banyak dilakukan. Para ahli dan peneliti bidang kepemimpinan telah mengembangkan terminologi kepemimpinan berdasarkan sifat, perilaku, pengaruh, pola interaksi, hubungan peran, dan kedudukan dalam suatu posisi administratif (Yukl, 2013). Menurut Day \& Sammons (2014) konsep kepemimpinan, manajemen dan administrasi mengalami tumpang tindih dalam penerapannya, namun seiring dengan perkembangan telah diberikan penekanan yang berbeda dari waktu ke waktu dan dalam konteks yang berbeda, sehingga penggunaannya bervariasi di berbagai negara dengan budaya profesional yang berbeda. Lebih lanjut Day \& Sammons (2014) menjelaskan perbedaan penekanan kepemimpinan dan manajemen ini mencerminkan variasi dalam fungsi sistem pendidikan dan konteks kebijakan, tetapi muara dari kepemimpinan ada pada peran 
pemimpin itu sendiri. Kepemimpinan dan manajemen bukanlah merupakan terma yang sinonim, seseorang bisa menjadi manajer tanpa harus menjadi seorang pemimpin, sebaliknya seseorang bisa me-manage tanpa harus memimpin (Bush \& Coleman, 2012).

Kemampuan manajemen kepemimpinan berpengaruh terhadap perubahan organisasi. Dimensi perubahan tersebut diantaranya tergambar dari perubahan budaya sekolah, komitmen organisasi warga sekolah, motivasi mengajar guru, kualitas pembelajaran, dan sebagai outputnya adalah prestasi siswa. Hasil studi literatur utama dari beberapa buku dan hasil penelitian terdahulu, mengungkapkan bahwa kepemimpinan dengan berbagai gaya (style) tertentu memiliki kontribusi bagi kemajuan suatu organisasi, seperti halnya gaya kepemimpinan transformatif. Ada hubungan positif dan signifikan antara kepemimpinan transformasional dan iklim sekolah (Lestari et al., 2018; Mccarley et al., 2014). Sementara, terdapat hubungan positif dan sangat signifikan antara variabel iklim organisasi dengan variabel produktivitas kerja guru (Lestari et al., 2018). Iklim organisasi dan kepemimpinan transformatif berpengaruh besar terhadap kinerja guru (Prasetyo, 2021). Tugas pemimpin transformasional adalah menginspirasi, merangsang secara intelektual, dan memberi perhatian secara individual, berdeda dengan kepemimpinan transaksional yang mempraktikkan penguatan kontingen pengikut atau bawahan (Bass, 2012). Di sekolah sendiri, kepala sekolah dapat memainkan peran kunci dalam meningkatkan pengajaran dan prestasi siswa (Herrmann et al., 2019). Kepala sekolah sebagai pemimpin lembaga pendidikan di tingkat sekolah dituntut memiliki kemampuan kepemimpinan yang dapat mendorong sekolah mewujudkan keunggulan sekolah untuk mampu bersaing meraih kemajuan.

Berdasarkan hasil pengamatan empiris yang dilakukan penulis, bahwa sekolah belum menunjukkan adanya perubahan kemampuan kepemimpinan seiring dengan perubahan yang terjadi sekarang ini. Tantangan kepemimpinan sekolah terletak pada kemampuan berinovasi dibidang pembelajaran, menajemen sumber daya manusia, manajemen sarana dan prasarana, dan manajemen keuangan sekolah yang transparan dan akuntabel. Mansor et al. (2020) mengungkapkan bahwa tantangan yang dihadapi sekolah sekarang ini berupa: kendala keuangan, infrastruktur yang bobrok, kurangnya sumber daya manusia, dan masalah kompetensi guru. Di masa sulit sekarang, ditengah Pandemi Covid 19, sekolah menghadapi situasi yang tidak menentu, sekolah dituntut untuk memiliki kemampuan menyesuaikan diri dengan situasi yang ada, merumuskan strategi kepemimpinan yang baru dan tanggap terhadap perubahan. Yukl (2013) menjelaskan dalam teori kontinjensi strategis bahwa semua organisasi harus mengatasi situasi kritis, terutama masalah dalam proses teknologi yang digunakan untuk menjalankan operasi dan masalah dalam beradaptasi dengan kejadian tak terduga di lingkungan. Menurut Yukl (2013) suatu masalah menjadi kritis jika masalah itu jelas penting untuk kelangsungan hidup dan kemakmuran organisasi. Sehingga diperlukan anggota organisasi yang memiliki keahlian dalam memecahkan masalah kritis yang dihadapi.

Dengan merujuk beberapa literatur terkait dan analisis terhadap berbagai hasil penelitian yang relevan dengan topik kajian, artikel ini mengkaji tentang variabel kepemimpinan sekolah dalam mewujudkan keunggulan, mampu menghadapi persaingan ditengah perubahan situasi yang begitu cepat dengan menawarkan manajemen kepemimpinan yang diperlukan untuk situasi sekarang. Artikel ini dirumuskan atas dasar asumsi bahwa efektifitas kepemimpinan merupakan penentu kemajuan organisasi dengan kekuasaan, wewenang, dan pengaruh yang melekat didalamnya. Yukl (2013) menjelaskan bahwa efektivitas organisasi adalah kemakmuran jangka panjang dan kelangsungan hidup organisasi. Yukl memandang bahwa untuk menjadi organisasi yang sukses harus beradaptasi dengan lingkungan mereka, memperoleh sumber daya yang diperlukan, dan melakukan operasi dengan cara yang efisien. Menurut Yukl, 
pemimpin dapat mempengaruhi kinerja organisasi dalam beberapa cara, termasuk keputusan tentang strategi kompetitif, sumber daya manusia, dan program manajemen, sistem, dan struktur organisasi (Yukl, 2013). Dalam konteks organisasi sekolah, kepala sekolah yang efektif memberikan visi dan arah yang jelas bagi sekolah (Day \& Sammons, 2014).

Penelitian ini difokuskan pada kajian tentang manajemen kepemimpinan pendidikan pada tingkat organisasi sekolah untuk mewujudkan keunggulan kompetitif. Tujuan penelitian ini adalah menganalisis tentang indikator-indikator manajemen kepemimpinan yang menentukan kemajuan sekolah. Hasil penelitian ini bermanfaat sebagai rujukan dalam memahami berbagai indikator yang menunjukkan keunggulan sekolah, sehingga sekolah memiliki kemampuan menghadapi persaingan.

\section{METODE}

Penelitian ini menggunakan metode library research (penelitian kepustakaan), yakni dengan cara mengumpulkan data-data yang relevan dari buku, jurnal, majalah, dan lain sebagainya tanpa harus melakukan tinjauan ke lapangan. Penelitian kepustakaan merupakan suatu penelitian yang memanfaatkan sumber perpustakaan untuk memperoleh data penelitian (Zed, 2004). Sumber pustaka yang menjadi rujukan dalam penelitian ini adalah bersumber dari Buku, Jurnal internasional dan nasional yang relevan dengan topik penelitian. Data yang diperlukan dalam penelitian ini bersifat kualitatif tekstual dengan menggunakan pijakan terhadap statement dan proporsi-proporsi ilmiah yang dikemukakan oleh para pakar dan peneliti yang erat kaitannya dengan topik pembahasan. Waktu penelitian ini dilaksanakan selama tiga bulan, dimulai dengan melakukan pengumpulan terhadap buku-buku dan jurnal, kemudian analisis kesesuaian topik dan tema riset dengan tema penelitian ini. Sementara itu, deskripsi hasil penelitian dilakukan dengan mendeskripsikan berbagai indikator manajemen kepemimpinan untuk mewujudkan keunggulan kompetitif sekolah.

\section{HASIL DAN PEMBAHASAN}

Berdasarkan hasil analisis terhadap buku-buku dan jurnal ilmiah yang digunakan dalam penelitian bahwa indikator manajemen kepemimpinan untuk mewujudkan keunggulan sekolah, mencakup: aspek organisasi, pembelajaran, sumber daya (manusia dan sarana prasarana), dan budaya organisasi. Indikator manajemen tersebut menjadi penentu bagi keunggulan sekolah. Sehingga manajemen kepemimpinan pendidikan oleh para pemimpin sekolah harus lebih banyak difokuskan pada terpenuhinya indikator-indikator tersebut. Adapun hasil analisis mengenai indikator-indikator tersebut dapat dideskripsikan berikut.

\section{Aspek Organisasi}

Modernisasi manajemen merupakan aspek penting yang tidak bisa diabaikan. Di era sekarang ini, adopsi manajemen organisasi yang modern menjadi hal penting untuk dilakukan. Manajemen tidak bisa dianggap sebagai suatu aspek institusi pendidikan yang jumud dan tidak bisa diubah (Bush \& Coleman, 2012). Seorang pemimpin organisasi dapat mengembangkan manajemen yang sesuai dengan tuntutan perkembangan. Manajemen sekolah perlu diarahkan kepada pengembangan kualitas sekolah secara menyeluruh. Salah satu model manajemen organisasi yang dapat dikembangkan adalah manajemen mutu terpadu (total quality management). Menurut Sallis (2010) manajemen mutu terpadu adalah sebuah filosofi tentang perbaikan secara terusmenerus, yang dapat memberikan seperangkat alat praktis kepada setiap institusi pendidikan dalam memenuhi kebutuhan, keinginan, dan harapan para pelanggannya, saat ini dan untuk masa yang akan datang. Total quality management tidak hanya untuk mencapai kualitas yang lebih tinggi, tetapi juga mempengaruhi semua segmen dalam proses pendidikan di sekolah, seperti: manajemen organisasi, hubungan interpersonal, material, dan sumber daya manusia (Khurniawan et al., 2020). Total quality management dan 
interpersonal communication (komunikasi interpersonal) berpengaruh positif dan signifikan terhadap kepuasan siswa, baik secara langsung maupun melalui mediasi kualitas layanan (Dewi et al., 2019).

Kemajuan informasi teknologi yang semakin cepat mendorong perubahan tatakelola organisasi dalam segala dimensi, termasuk dimensi keuangan. Di bidang keuangan, sekolah perlu mengadopsi sistem manajemen informasi dan administrasi keuangan terintegrasi. Salah satu model manajemen yang dapat diterapkan adalah sistem manajemen keuangan terpadu. Pengenalan Sistem Manajemen Keuangan Terpadu (IFMIS) telah menjadi komponen inti dari reformasi keuangan untuk mempromosikan efisiensi, keamanan manajemen data dan pelaporan keuangan yang komprehensif (Chêne, 2009). EMIS merupakan sekumpulan informasi sekolah yang telah diorganisir sebagai bahan bagi sekolah untuk menyusun perencanaan dan pengambilan keputusan. EMIS adalah sebuah metode manajemen formal dalam penyediaan informasi pendidikan yang akurat dan tepat waktu, sehingga proses pengambilan keputusan, perencanaan, pengembangan proyek, dan fungsi-fungsi manajemen pendidikan lainnya dapat dilaksanakan secara efektif (Sina et al., 2020). Di era sekarang, salah satu alternatif manajemen keuangan sekolah terutama di era sekarang ini adalah pengembangan sistem manajemen keuangan sekolah berbasis website untuk mendukung pengelolaan administrasi keuangan sekolah terutama di masa pandemi Covid-19, guna mendukung kebijakan pemerintah dalam upaya digitalisasi layanan administrasi dan keuangan di sekolah (Winarno et al., 2020). Penerapan sistem infomasi manajemen berpengaruh secara signifikan terhadap kualitas proses pengambilan keputusan yang dilakukan oleh kepala sekolah (Supriadi et al., 2021).

\section{Aspek Pembelajaran}

Kualitas proses pembelajaran menjadi salah satu indikator yang menentukan keunggulan sekolah. Digitalisasi kegiatan pembelajaran menjadi ukuran bahwa sekolah memiliki keunggulan untuk bersaing. Teknologi telah merevolusi dunia pendidikan, penerapan teknologi di sekolah tidak dapat diabaikan, fakta menunjukkan, dengan munculnya komputer dalam pendidikan, menjadi lebih mudah bagi guru untuk memberikan pengetahuan dan bagi siswa untuk memperolehnya, sehingga penggunaan teknologi telah membuat proses belajar mengajar menjadi lebih menyenangkan (Raja \& Nagasubramani, 2018). Digitalisasi bidang pendidikan dapat dilaksanakan pada tataran: administrasi, belajar-mengajar, evaluasi, penelitian, dan pengembangan sekolah (Bejinaru, 2013).

Pelaksanaan kegiatan belajar mengajar di sekolah dapat memaksimalkan penggunaan teknologi sebagai instrumen untuk mewujudkan kualitas pembelajaran. Dengan adanya kemajuan informasi dan teknologi seperti sekarang ini, semua aktivitas pembelajaran diarahkan pada penggunaan teknologi dengan model pembelajaran online (e-learning). Oleh karenanya, kualitas guru menjadi penentu terciptanya kualitas pembelajaran. Kompetensi guru berpengaruh terhadap motivasi belajar (Alif et al., 2020). Kompetensi, kinerja guru, dan kepemimpinan kepala sekolah baik secara parsial maupun simultan berpengaruh terhadap mutu pendidikan, dan kompetensi berpengaruh dominan terhadap mutu pendidikan (Suryati et al., 2020). Kepala sekolah harus menjadi pemimpin instruksional (pembelajaran), kepala sekolah harus banyak menghabiskan waktu untuk pembinaan dan evaluasi guru, pengembangan program sekolah, dan memprediksi perolehan prestasi siswa yang positif (Grissom et al., 2013). Berdasarkan beberapa hasil penelitian tersebut, kepala sekolah sebagai pemimpin pembelajaran di sekolah didesak untuk melakukan penyesuaian tatakelola pembelajaran di sekolah. Semua aktivitas pembelajaran yang dilaksanakan tidak bisa lagi mengandalkan kegiatan pembelajaran secara konvensional. Para guru harus mulai membiasakan diri menggunakan media pembelajaran online $(e-$ learning) dengan menggunakan aplikasi pembelajaran yang ada sekarang. 


\section{Aspek Sumber Daya}

Aspek sumber daya merupakan bagian penting sebagai penggerak kemajuan sekolah, baik sumber daya manusia maupun sumber daya material. Sumber daya manusia yang mencakup kesiapan siswa, kualitas guru, dan kemampuan staf merupakan penentu kemajuan sekolah. Demikian halnya dengan sumber daya material, seperti sarana dan prasarana pembelajaran. Alif et al. (2020) dalam penelitiannya mengungkapkan bahwa kompetensi guru berpengaruh terhadap motivasi belajar, fasilitas belajar mempengaruhi motivasi belajar, kesiapan siswa mempengaruhi motivasi belajar, dan motivasi belajar berpengaruh terhadap prestasi belajar. Oleh karenanya, di era perubahan sekarang kepala sekolah harus memiliki strategi manajemen yang efektif dan tanggap terhadap perubahan. Wening \& Santosa (2020) mengungkapkan bahwa strategi kepala sekolah adalah untuk meningkatkan kualitas sumber daya manusia di bidang TIK dalam hal fasilitas dan infrastruktur, keterbukaan dengan perkembangan untuk menghadapi hal-hal yang akan terjadi di era digital 4.0, reaksi cepat yang akan dilakukan dalam menghadapi perubahan di era 4.0, berorientasi pada proses dan hasil, dan menguasai formula $4 \mathrm{C}$, yaitu: berpikir kritis, kreativitas, komunikasi, kolaborasi.

Sementara itu, Day \& Sammons (2014) mengungkapkan bahwa kepala sekolah yang efektif memberikan visi dan arah yang jelas bagi sekolah, memiliki skala prioritas, memusatkan perhatian pada guru dan staf, dan membiarkan guru untuk mengembangkan inisiatif yang akan berdampak pada pencapaian prestasi siswa. Para pemimpin sekolah memperbaiki proses belajar mengajar secara tidak langsung dan pengaruh yang paling besar adalah melalui pemberian motivasi pada guru dan staf, menunjukkan komitmen dan membangun kondisi yang baik untuk bekerja (Sanusi, 2013). Artinya kepemimpinan kepala sekolah secara tidak langsung berpengaruh terhadap prestasi siswa, tetapi melalui kemampuan kepemimpinan kepala sekolah memberikan motivasi dan bimbingan kepada para guru dan staf. Hasil penelitian Surachmi (2011) menunjukkan bahwa dimensi-dimensi internal seperti kejelasan misi sekolah, organisasi pembelajaran, peningkatan praktik pembelajaran, dan peningkatan iklim sekolah berhubungan dengan praktik kepemimpinan instruksional kepala sekolah dengan persentase hubungan sebesar $91,22 \%$.

\section{Aspek Budaya Organisasi}

Budaya organisasi merupakan variabel yang berpengaruh terhadap kinerja sebuah organisasi. Budaya organisasi terdiri dari asumsi, keyakinan, dan nilai bersama bagi para anggotanya. Budaya organisasi fokus terhadap nilai-nilai, keyakinan-keyakinan, dan norma-norma individu dan bagimana persepsi-persepsi ini bergabung atau bersatu dalam makna-makna organisasi (Bush \& Coleman, 2012). Keyakinan dan nilai-nilai yang mendasari membantu anggota menghadapi masalah kelangsungan hidup di lingkungan eksternal dan menjaga integrasi internal (Yukl, 2013). Budaya setiap organisasi berbeda-beda, ada yang kuat ada juga yang lemah, atau mungkin ada satu budaya dominan dalam sebuah organisasi. Budaya organisasi dibentuk oleh anggota organisasi sebagai bentuk kesepakatan moral, tetapi ada juga karena pengaruh situasional pemimpin, karena seiring perkembangan waktu pemimpin juga dapat mempengaruhi budaya (Yukl, 2013). Budaya organisasi memiliki hubungan yang kuat dengan kepemimpinan, karena budaya sangat mempengaruhi berlakunya kepemimpinan (Bush, 2021). Untuk menciptakan budaya organisasi yang kondusif, maka peran pemimpin organisasi menjadi sangat menentukan.

Kepala sekolah sebagai pemimpin sekolah berperan penting dalam menciptakan budaya organisasi yang mendukung kinerja guru dan staf. Budaya organisasi mendukung semangat kerja guru-guru. Oleh karenanya, kepala sekolah perlu menerapkan manajemen kepemimpinan yang dapat mengembangkan tumbuh suburnya budaya kerja guru. Di seluruh negeri, kepemimpinan yang berkualitas dan iklim sekolah yang positif 
sangat penting bagi keberhasilan setiap kepala sekolah, siswa, dan sekolah (Mccarley et al., 2014). Dengan demikian, kepemimpinan pendidikan di tingkat sekolah dituntut untuk mampu mengadopsi pendekatan kepemimpinan yang sesuai dengan konteks perubahan sekarang ini. Di tengah ketidakpastian situasi dan kondisi, setiap pemimpin pendidikan perlu menerapkan strategi kepemimpinan yang efektif. Kepala sekolah dituntut untuk mampu mengembangkan budaya kerja yang sesuai dengan perkembangan kehidupan sosial budaya masyarakat. Beauchamp et al. (2021) dalam penelitiannya mengungkapkan bahwa ditengah situasi yang tidak pasti karena pandemi, kepala sekolah perlu mengembangkan pendekatan pragmatis nilai dan sikap, moral dan emosional, bekerja untuk kebaikan bersama, dan meningkatkan hubungan pribadi dengan orangtua, staf, murid, dan berbagai lembaga eksternal. Peran kepemimpinan kepala sekolah dalam mendukung budaya dan mutu sekolah sangat berpengaruh dalam meningkatkan kualitas sekolah (Marni et al., 2021).

\section{KESIMPULAN}

Berdasarkan uraian pada bagian hasil dan pembahasan di atas, maka hasil penelitian dapat disimpulkan bahwa manajemen kepemimpinan pendidikan yang diterapkan di tingkat sekolah dalam rangka mewujudkan keunggulan kompetitif sekolah difokuskan pada beberapa indikator manajemen kepemimpinan, yakni mencakup: aspek organisasi, pembelajaran, sumber daya (manusia dan sarana prasarana), dan budaya organisasi. Dari hasil studi pustaka terhadap beberapa buku, jurnal international dan nasional yang relevan dengan topik penelitian, indikator tersebut menunjukkan pengaruh signifikan terhadap keunggulan sekolah dalam menghadapi persaingan.

\section{SARAN}

Mengacu pada kesimpulan analisis dapat disarankan kepada para pemimpin lembaga pendidikan agar lebih banyak menaruh perhatian terhadap perbaikan dari beberapa indikator tersebut. Meski demikian, hasil studi ini juga perlu dilakukan proses pembuktian lebih lanjut melalui studi lapangan dengan menggunakan berbagai pendekatan penelitian, baik secara kualitatif maupun secara kuantitatif, dengan mengambil fokus kajian yang lebih luas dan mendalam tentang indikator manajemen kepemimpinan sekolah, dengan harapan hasil studi selanjutnya dapat memperkaya hasil studi ini, sehingga temuan-temuan yang akan datang berkontribusi bagi pengembangan manajemen kepemimpinan di bidang pendidikan.

\section{UCAPAN TERIMAKASIH}

Penulis menyampaikan ucapan terimakasih kepada teman-teman dosen yang telah menemani sebagai teman diskusi selama pelaksanaan studi ini. Ide dan saran masukan yang membangun yang disampaikan sangat bermanfaat bagi kami selama pelaksanaan studi ini sehingga karya ini dapat dipublikasikan.

\section{DAFTAR PUSTAKA}

Alif, M. H., Pujiati, A., \& Yulianto, A. (2020). The Effect of Teacher Competence, Learning Facilities, and Learning Readiness on Students , Learning Achievement Through Learning Motivation of Grade 11 Accounting Lesson in Brebes Regensy Vocational High School. Journal of Economic Education, 9(2), 151-161. https://journal.unnes.ac.id/sju/index.ph p/jeec/article/view/40155/16625.

Bass, B. M. (2012). Two Decades of Research and Development in Transformational Leadership. European Journal of Work and Organizational Psychology, 8(1), 9-32. https://doi.org/http://dx.doi.org/10.108 0/135943299398410

Beauchamp, G., Hulme, M., Clarke, L., Hamilton, L., \& Harvey, J. A. (2021). 'People miss people': A study of school leadership and management in the four nations of the United Kingdom in the early stage of the COVID-19 pandemic. Educational 
Management Administration and Leadership, 49(3), 375-392. https://doi.org/10.1177/174114322098 7841

Bejinaru, R. (2013). Impact of Digitalization on Education in the Knowledge Economy. Management Dynamics in the Knowledge Economy, 7(3), 367380.

https://doi.org/10.25019/mdke/7.3.06

Bush, T. (2021). School leadership and culture: Societal and organisational perspectives. Educational Management Administration and Leadership, 49(2), 211-213. https://doi.org/10.1177/174114322098 3063

Bush, T., \& Coleman, M. (2012). Manajemen Mutu Kepemimpinan Pendidikan (Cet. I). Jogjakarta: IRCiSoD.

Chêne, M. (2009). The Implementation of Integrated Financial Information Management Systems ( IFMIS ). AntiCorruption Resources Centre, Transparency International., April, 111.

https://www.u4.no/publications/theimplementation-of-integratedfinancial-management-systemsifmis.pdf.

Day, C., \& Sammons, P. (2014). Successful School Leadership. UK: Education Development Trust. https://www.educationdevelopmenttrust.c om/files/a3/a359e571-7033-41c7-8fe79ba60730082e.pdf.

Dewi, H. P., Prihatin, L., \& Matondang, R. (2019). Implementation of Total Quality Management and Interpersonal Communication in Achieving Student Satisfaction through Service Quality at Yayasan Pendidikan Islam, Miftahussalam, Medan. International Journal of Research and Review, 2(6), 111-129. http://www.gkpublication.in/IJRR_Vo 1.2_Issue6_June2015/IJRR0066.pdf

Grissom, J. A., Loeb, S., \& Master, B. (2013). Effective Instructional Time Use for School Leaders: Longitudinal
Evidence From Observations of Principals. Educational Researcher, 42(8), 433-444. https://doi.org/10.3102/0013189X135 10020

Herrmann, M., Clark, M., James-Burdumy, S., Tuttle, C., Kautz, T., Knechtel, V., Dotter, D., Wulsin, C. S., Deke, J., \& (ED), N. C. for E. E. and R. A. (2019). The Effects of a Principal Professional Development Program Focused on Instructional Leadership. NCEE 20200002. National Center for Education Evaluation and Regional Assistance, October, 2019.

Jackson, K. M. (2019). A Review of Research Methods Trends in Educational Leadership Journals. Education Leadership Review, 20(1), 119-132.

Khurniawan, A. W., Sailah, I., Muljono, P., Indriyanto, B., \& Maarif, M. S. (2020). An Analysis of Implementing Total Quality Management in Education: Succes and Challenging Factors. International Journal of Learning and Development, 10(2), 4459.

https://doi.org/https://doi.org/10.5296/ ijld.v10i2.17270

Lestari, A., Hidayat, N., \& Putra, K. S. (2018). Hubungan Antara Kepemimpinan Transformasional dan Iklim Organisasi dengan Produktivitas Kerja Guru. Jurnal Manajemen Pendidikan, 6(2), 672-682.

Mansor, A. N., Hamid, A. H. A., Medina, N. I., Vikaraman, S. S., Lail, J., \& Wahab, A. (2020). Challenges and strategies in managing small schools : A case study in Perak, Malaysia. Educational Management Administration \& Leadership, 20(10), $1-17$. https://doi.org/10.1177/174114322094 2517

Marni, P. Y. M., Riyanto, Y., \& Widodo, B. S. (2021). Peran Kepemimpinan Kepala Sekolah dalam Mendukung Budaya dan Mutu SMPK Angelus Custos II Surabaya. Jurnal Ilmiah 
Mandala Education, 7(3), 249-266. https://doi.org/10.36312/jime.v7i3.221 3

Mccarley, T. A., Peters, M. L., \& Decman, J. M. (2014). Transformational Leadership Related To School Climate: A Multi-Level Analysis. Educational Management Administration \& Leadership, 11(3), $1-21$.

https://doi.org/10.1177/174114321454996 6

Prasetyo, M. A. M. (2021). The Effects of Organizational Climate and Transformative Leadership on Islamic Boarding School Teacher Performance. Jurnal Manajemen, Kepemimpinan, Dan Supervisi Pendidikan, 6(2), 214-235. https://doi.org/10.31851/jmksp.v6i2.5 595

Raja, R., \& Nagasubramani, P. C. (2018). Impact of modern technology in education. Journal of Applied and Advanced Research, 3(1), 33-35. https://doi.org/10.21839/jaar.2018.v3is 1.165

Sallis, E. (2010). Total Quality Management In Education: Manajemen Mutu Pendidikan (Cet. Ke-I). Jogjakarta: IRCiSoD.

Sanusi, A. (2013). Kepemimpinan Pendidikan. Bandung: Nuansa Cendekia.

Sina, R., Fatmawati, \& Mahsyar, A. (2020). Penerapan Education Management Information System (EMIS) di Lembaga Pendidikan Keagamaan dan Pondok Pesantren pada Kantor Kementerian Agama Kota Makassar. JPPM: Journal of Public Policy and Management, 1(1). https://journal.unismuh.ac.id/index.ph p/jppm/article/download/2704/pdf.

Supriadi, D., Usman, H., \& Jabar, C. S. A. (2021). The Moderation Effect of Information Systems on Vocational High School Principal DecisionMaking Model. Cakrawala Pendidikan, 40(1), 43-55. https://doi.org/10.21831/cp.v40i1.312 68

Surachmi, S. (2011). Efektivitas Dimensi Internal Kepala Sekolah dalam Kepemimpinan Pembelajaran. Cakrawala Pendidikan, 30(3), 430439.

https://doi.org/https://doi.org/10.21831 /cp.v3i3.4206

Suryati, A. I., Arifin, S., \& Yarnest. (2020). The Influence of Teacher Performance and School Culture on School Quality. Journal of Business and Management (IOSR-JBM), 22(6), 52-61. https://doi.org/10.2991/assehr.k.20120 1.015

Wening, M. H., \& Santosa, A. B. (2020). Strategi Kepemimpinan Kepala Sekolah Dalam Menghadapi Era Digital 4.0. JMKSP (Jurnal Manajemen, Kepemimpinan, Dan Supervisi Pendidikan), 5(1), 56. https://doi.org/10.31851/jmksp.v5i1.3 537

Winarno, A., Agustina, Y., \& Vinola, R. (2020). Developing website-based school financial administrative management system during covid-19 pandemic. International Journal of Business, Economics and Law, 22(1), 167-172. https://www.ijbel.com/wpcontent/uploads/2020/11/IJBEL22_24 2.pdf.

Yukl, G. (2013). Leadership In Organization (Eighth Edi). USA: Prentice Hall.

Zed, M. (2004). Metode Penelitian Kepustakaan. Jakarta: Yayasan Obor Nasional. 